\title{
Comparison on Factor of Safety using Different Method of Analysis for Slope Stability
}

Siti Noorliyana Mohd Pami1 ${ }^{1}$ Norfarah Nadia Ismail2*, Ahmad Bukhari Ramli1

${ }^{1}$ Department of Civil Engineering, International Islamic University Malaysia, 53100 Kuala Lumpur, Malaysia.

${ }^{2}$ School of Civil Engineering, College of Engineering, Universiti Teknologi MARA, Shah Alam 40450 Selangor, Malaysia.

"corresponding author: norfarahnadia@uitm.edu.my

\section{ABSTRACT}

Currently, the construction of slope is increasing; thus, the risk of slope to fail also increases. The series of landslide that happened to man-made slope has been recorded since the early of 1993 until now. Many efforts such as treating the critical slope, redesigning the failed slope, and analysing the stability of the slope have been done. However, landslide is still happening in Malaysia. The factor of safety (FOS) from the stability analysis that is commonly used might not be adequate to determine the safety of the slope in Malaysia. Therefore, in this study, the optimum factor of safety was obtained by using three methods of slice; Bishop's Simplified method, Spencer method, and Morgenstern-Price method which have been used in many projects. A study place was selected in Ladang Balau, Semenyih, in Selangor and from the CIU test, the important soil parameter for slope was extracted to analyse the slope stability using SLOPE/W and manual calculation. The lambda for Spencer method and Morgenstern-Price method was generated for further discussion on the relationship between lambda and factor of safety. The data generated from both calculation methods, from manual and software, were discussed and the next ideal method to achieve the optimum factor of safety was determined. The factor of safety for every method is basically influenced by the interslice shear force presence but not Bishop's Simplified method as the moment equilibrium is insensitive towards interslice force function. For lambda, the factor that influences the value is the function used which included constant and half-sine function; however, for Bishop's Simplified method, the lambda is equal to zero as the method ignores the interslice shear force. Thus, the Morgenstern-Price method was chosen to be the best method to generate a good factor of safety.

Keywords: slope stability, Morgenstern-Price method, SLOPE/W, factor of safety

\subsection{INTRODUCTION}

Method of slices is the common method used to check the factor of safety (FOS) of slopes. This method was developed in 1927 by Fellenius which then led to the development of the method in order to accommodate the complex problem of slope. Finally, in 1965, Morgenstern-Price (M-P) came with a new method called the 'bestfit regression'. In 1977, a computer software SLOPE/W was developed by Professor D. G. Fredlund at the University of Saskatchewan [1].

Since 1980s, land development in Malaysia has increased; hence, causing unavailability of suitable low land for further development. Therefore, the development of highland or hilly terrain has increased over the year as the demand for infrastructure increased from the client [2]. Many efforts such as treating the critical slope, redesigning the failed slope, and analysing the stability of the slope have been done. Thus, this study compared the value of the FOS by applying different types of method of analysis using slope data in Malaysia. Different method of analysis may give different value of FOS.

The objectives of this study are to analyse the factor of safety of slopes using conventional methods and computer software SLOPE/W, to compare the factor of safety obtained from different methods of calculation, and to compare the lambda, $\lambda$, mainly for Spencer's method and Morgenstern-Price method. However, there is a limitation to this study as the method of slices used is only up to three methods; Bishop's Simplified method, Spencer method, and Morgenstern-Price method. By comparing the results obtained from these three methods, this reasearch can project the best method to be used in order to select the most optimum factor of safety for the slope stability analysis. This will help in preventing mistakes made in the calculation of FOS.

The computer software used for this study was SLOPE/W by GeoStudio while manual calculation was done by using Microsoft Excel, and the study place was only limited to Ladang Balau, Semenyih, Selangor. The study place was only limited to the state level. 


\subsection{Literature review}

In order to avoid slope failure, slope stability analysis must be done and the factor of safety is a major concern. The calculation of the minimum factor of safety (FOS) against sliding or shear failure is important in order to analyse the stability of the slope. Factor of safety for slope stability is given as the ratio of the ultimate shear strength divided by the mobilized shear stress at incipient failure [3-6].

According to [6], there are two types of slopes which are natural and engineered slopes. Natural slopes are usually disrupted because of the projects that intersect with the ridges and alley which can lead to slope stability problems. For engineered slope, there are three types of slope; embankment, cut slopes, and retaining walls [6]. According to [7], the typical slope profile and geometry for fill slopes and embankments, and the gradient of the slope must be $1 \mathrm{~V}: 2 \mathrm{H}$ while the design must have a minimum $2 \mathrm{~m}$ of berm width and a maximum of $6 \mathrm{~m}$ berm height for all untreated fill slopes and embankments.

Landslide is the common failure for the slope. According to [8], there are five types of landslide movement which are, falling, toppling, sliding, spreading and flowing. For the causes of slope failure, there are two opinions. [6] in his book generally said that the cause of the slope failure is due to the increasing shear stress and decreasing in the shear strength of the soil mass while [9] only focused on the factor that causes the increase in shear stresses such as erosion, rainfall, earthquakes, geological features, external loading, construction activities, and rapid drawdown.

To determine the stability of the slope, method of slices is widely used in order to obtain the factor of safety. This is because the method of slices can work with complex slope geometry, variety of soil conditions, and also the influence of external boundary loads [6]. This slope stability analysis will divide a slide-mass into $n$ smaller slices [6]. The width, $b$ of each slice does not have to be the same and the base of each slice is assumed as a straight line while the height is measured from the centre-line [10]. The list of common methods of analysis and the conditions of static equilibrium that determine the Factor of Safety (FOS) is presented in Table 1.

Table 1: Static Equilibrium Conditions Satisfied by Limit Equilibrium Method [1]

\begin{tabular}{llcc}
\hline Method & \multicolumn{2}{c}{ Force Equilibrium } & Moment \\
\cline { 2 - 3 } & $X$ & $Y$ & Equilibrium \\
\hline Ordinary Method of Slices (OMS) & No & No & Yes \\
Bishop's Simplified & Yes & No & Yes \\
Janbu's Simplified & Yes & Yes & No \\
Lowe and Karafiath's & Yes & Yes & No \\
Corps of Engineers & Yes & Yes & No \\
Spencer's & Yes & Yes & Yes \\
Bishop's Rigorous & Yes & Yes & Yes \\
Janbu's Generalized & Yes & Yes & No \\
Sarma's & Yes & Yes & Yes \\
Morgenstern-Price & Yes & Yes & Yes \\
\hline
\end{tabular}

As computer technology development has improved throughout the year after the method of slices was introduced to the world in 1977, SLOPE/W by GeoStudio has been used and Professor D. G. Fredlund from University of Saskatchewan was the person responsible in developing the code [1].

From the analysis using the SLOPE/W, the factor of safety is obtained. There are a few opinions on the value of factor of safety. According to [9], the range for factor of safety is 1.15 to 1.5; the factor of safety for mining industry where the tailing dams are designed is FOS $\approx 1.1$ to 1.2 , common slopes such as those designed and cut for highway is FOS $\approx 1.3$, while dam uses FOS $\approx 1.4$. On the other hand, [4] stated that 1.25 to 1.40 is the range of global factor for natural slopes while for design purpose, factor of safety that ranges from 1.5 to 2.0 is needed. However, in Malaysia, [7] stated that for unreinforced slope, the minimum factor of safety is 1.3 while for reinforced or treated slope, the minimum FOS is 1.5 . Every project under JKR must follow this minimum safety factor; however, the minimum factor for safety of slope can be changed if the engineer already has experience with the particular type of soil.

\subsection{METHODOLOGY}

The study analysed the slope by using data from Ladang Balau, Semenyih, Selangor. The soil sample from the study place was taken to the lab for further test. One of the test was Isotropically Consolidated Undrained Triaxial Compression test (CIU) in order to obtain the effective friction angle, $\phi$ ' and cohesion, c' of the soil. These two parameters are needed to calculate the factor of safety using SLOPE/W. The flow of research methodology is shown in Fig. 1.

Analysis was performed using SLOPE/W, and Microsoft Excel for manual calculation. Analysis and discussion were mainly done using the information from SLOPE/W in the selection of the best method of slices. 


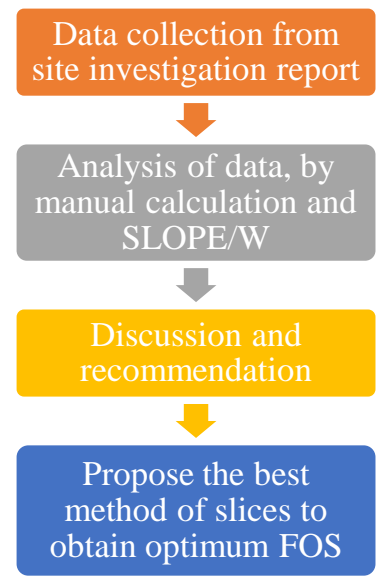

Figure 1. Flow of research methodology

The analysis of data using computer software was divided into four processes as shown in Fig. 2.

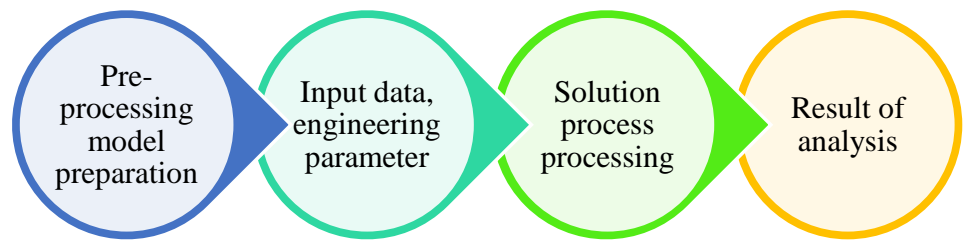

Figure 2. Process involved in analysis of data using SLOPE/W

\subsection{Pre-processing model peparation}

Pre-processing process includes the process creating the model of the slope in SLOPE/W. In order to get the factor of safety, the calculation used three methods; Bishop's Simplified method, Spencer method, and Morgenstern-Price method. The method can be changed in the SLOPE/W to get different result of FOS. The side function used was half-sine function and the pore water pressure (PWP) condition was represented by the Piezometric Line. Slip surface tab allows the user to choose the direction of movement of soil, slip surface option and tension crack option. The direction of movement was set from left to right while slip surface used in this study applied the Entry and Exit. The tension crack was set to no tension crack by default. The grid was set to $1 \mathrm{~m}$ for each $\mathrm{x}$ and $\mathrm{y}$-axis for easier application. It can be opened through the View tab to select the Grid while Sketch Axes can be accessed through the Sketch tab. The x-axis represents Distance and y-axis represents the Elevation of the slope. The slope model is sketched in 2-D shown in XY plane and sketched by selecting the Lines from Sketch tab and moving the cursor to the coordinates.

\subsection{Input data}

For SLOPE/W software, data such as the material or soil must be keyed in manually. Parameters such as unit weight of the soil, $\gamma$, the cohesion of the soil, c', and the friction angle, $\phi$ ' must be defined in this software. This parameter can be extracted from the site investigation report. Next, the region of each material is drawn by using borelog information as a guidance. If the pore water pressure is present between the materials within the depth, it can be drawn using Draw Piezometric Line in SLOPE/W. Lastly, for the slip surface option of Entry and Exit, the entry and exit point must be defined.

For manual calculation, the slope must be sliced manually but not necessarily having the same width for each of the slice. Next, the width and the height of each slice are determined. The soil parameters such as unit weight of soil, $\gamma$, cohesion, c', and friction angle for each of the slide are extracted from the soil investigation report. The inclination of slice top must also play an important role in the method of slice calculation. To ease the calculation, Microsoft Excel is used. The parameter is then substituted into the formula for each method.

For Bishop's Simplified method, the factor of safety could be obtained by equation (1):

$$
F S=\frac{1}{\sum W \sin \alpha} \sum \frac{c \beta+W \tan \varphi-\frac{c \beta}{F S} \sin \alpha \tan \varphi}{m_{\alpha}}
$$


where,

$$
m_{\alpha}=\cos \alpha+\frac{\sin \alpha \tan \varphi}{F S}
$$

For Spencer method, the factor of safety could be obtained by equation (2):

$$
F S=\frac{\left[W-\left(E_{R}-E_{L}\right) \tan \theta-\frac{c l \sin \alpha}{F}+\frac{u l \tan \varphi \sin \alpha}{F}\right.}{m_{\alpha}}
$$

\subsection{Solution process processing}

For SLOPE/W software, the software will verify to check whether all input parameters are defined appropriately to allow the software to run properly, then the software will begin to solve the problem. For manual calculation, the solution process will be done manually by applying the formula in Microsoft Excel. For SLOPE/W software, data such as the material or soil must be keyed in manually.

\subsection{Result of analysis}

When using computer software SLOPE/W, the result is calculated automatically by the software and at the end of the process, the result will show the lowest factor of safety for that particular method. For Spencer and Morgenstern-Price methods, the lambda, $\lambda$ is generated for each method for comparison.

For manual calculation, the result is obtained at the end of the calculation using Microsoft Excel after all parameters are substituted into the formula.

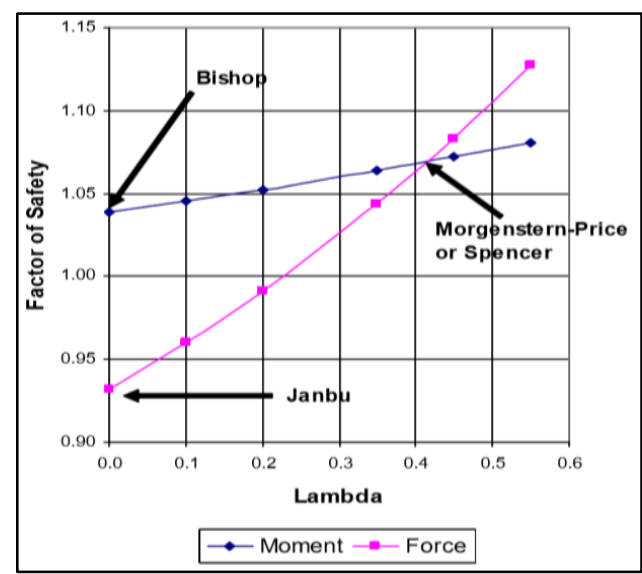

Figure 3. FOS for three main methods versus Lambda [1]

The factors of safety for three main methods in this study are compared and discussed. The minimum factor of safety is picked out from the three methods. The Bishop Simplified method may be the method that will give the lowest factor of safety; however, Spencer and Morgenstern-Price methods must be considered as well since the method takes into account both force and moment equilibrium values. This assumptions are made based on factor of safety versus lambda graph, as shown in Fig. 3. The manual calculation part is to prove that this study is not only based on the software but the calculation behind of the software is done to prove the understanding of the theory for each of the method.

The last process in this study is to propose the ideal method in order to generate the optimum factor of safety. This part of study is the summary from the discussion and recommendation. After the discussion and comparison of factor of safety part are done, the ideal method is chosen out of the three methods.

\subsection{RESULTS AND DISCUSSION}

A $12 \mathrm{~m}$ height slope model was used to demonstrate the capabilities of the three methods in order to compare the FOS and lambda by using manual calculation and the SLOPE/W software. The ratio of the slope was $1 \mathrm{~V}: 2 \mathrm{H}$ with a slope angle of $27^{\circ}$ (see Fig. 4). The geotechnical parameters used are presented in Table 2. This geotechnical parameters were obtained from site investigation report, where site investigation was done much earlier at the location site of Ladang Balau, Semenyih, Selangor. 


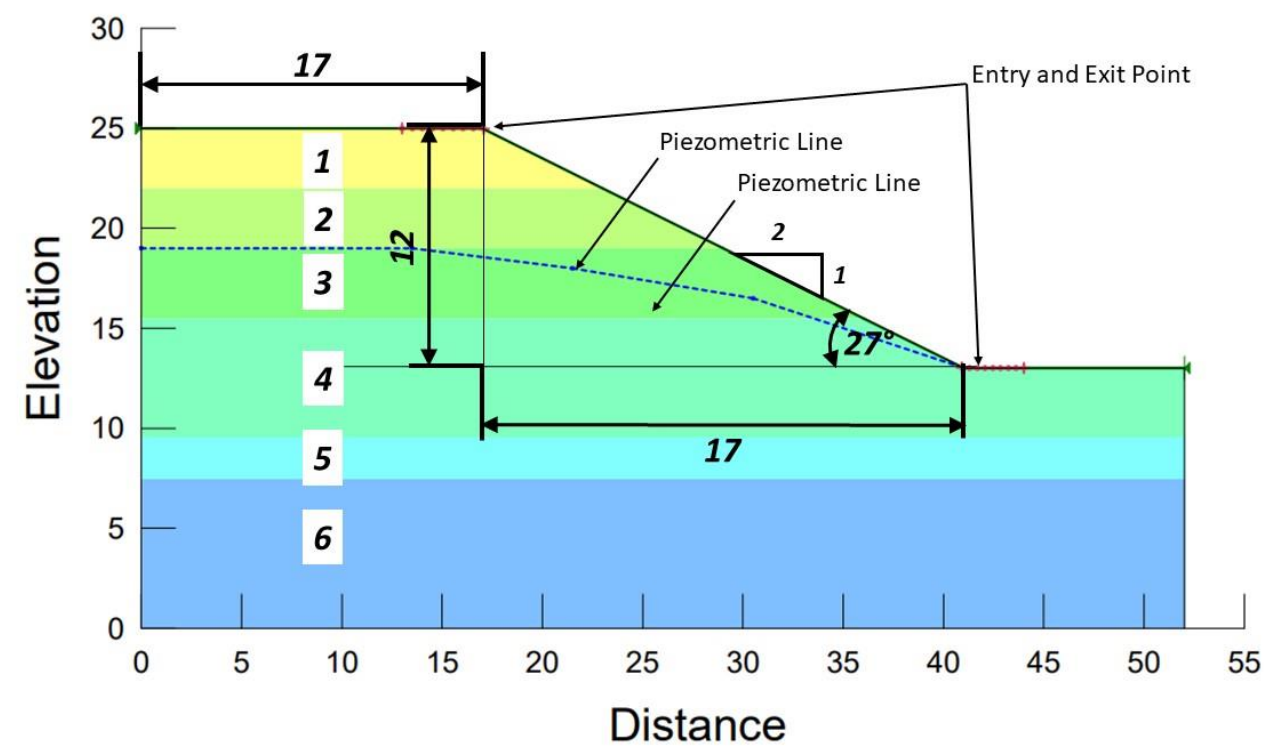

Figure 4. Slope profile

Table 2: Geotechnical parameters used in analysis

\begin{tabular}{ccccc}
\hline Layer & Name & $\begin{array}{c}\text { Unit Weight } \\
\left(\mathrm{kN} / \mathrm{m}^{3}\right)\end{array}$ & $\begin{array}{c}\text { Cohesion' } \\
(\mathrm{kPa})\end{array}$ & $\begin{array}{c}\text { Phi' } \\
\left({ }^{\circ}\right)\end{array}$ \\
\hline 1 & Firm Clay & 17 & 1 & 28 \\
2 & Stiff Silt & 18.9 & 2 & 28 \\
3 & Very Stiff Clay & 19 & 5 & 30 \\
4 & Very Stiff Silt & 19 & 7 & 32 \\
5 & Hard Silt & 20 & 10 & 36 \\
6 & Hard Layer & 21 & 11 & 37 \\
\hline
\end{tabular}

Table 3 is developed to summarise the FOS and lambda for each method. For the manual calculation, there are some limitations such as Spencer Charts can only measure the ${ }^{\prime}$ ' of only up to $40^{\circ}$. The advantages of using SLOPE/W are that the slice information can be obtained easily and can help to solve slope problem. It is different with manual calculation which needs higher understanding in order to solve one problem especially for M-P method.

Based on Fig. 5, the Bishop's Simplified FOS fell on moment curve as the primary assumption of the method was to ignore the interslice shear forces while it satisfied only moment equilibrium. When the interslice shear forces were ignored, the lambda was automatically equal to zero. However, for Spencer and M-P, FOS can be determined at the intersection of moments and force curve, as both method satisfied both moments and force equilibrium. Spencer only considered a constant X/E ratio for all slices while M-P method can use any general appropriate function. In this case, the function used by the M-P method was half-sine function as the SLOPE/W by default has set the function for that particular method.

Noted that, moment equilibrium is insensitive to the interslice shear forces while force equilibrium is vice versa. The reason is that sliding mass may not require any slippage between the slices to rotate. So, for the Bishop's Simplified method, the interslice shear can be assumed to be zero. This is because, when the moment equilibrium does not depend on the interslice shear, any assumption regarding the interslice force function becomes irrelevant. The interesting part is where the moment equilibrium curve is not always perfectly horizontal for circular slip surfaces as it is slightly inclined and the slope is nearly horizontal. Therefore, the FOS generated for Bishop's Simplified and M-P method is generally almost similar. In this case, the FOS for the three methods is almost similar with a difference of only 0.008 .

For comparison of lambda, Spencer method had a constant lambda along the slice, but for M-P method, the lambda varied and the highest lambda was chosen to represent the lambda of the whole method. In this case, the lambda of M-P method tended to be higher than Spencer because by default, the software was set into half-sine function to evaluate the M-P method. 
Table 3: Comparison of factors of safety

\begin{tabular}{cccccc}
\hline Method & Bishop's & \multicolumn{2}{c}{ Spencer's Method } & \multicolumn{2}{c}{ Morgenstern-Price Method } \\
\cline { 3 - 6 } & $\begin{array}{c}\text { Simplified } \\
\text { Method }\end{array}$ & FOS & $\lambda$ & FOS & $\lambda$ \\
\hline $\begin{array}{c}\text { Manual } \\
\text { calculation }\end{array}$ & 1.367 & 1.3 & - & 1.376 & - \\
$\begin{array}{c}\text { SLOPE/W } \\
\text { software }\end{array}$ & 1.367 & 1.375 & 0.41433 & 1.375 & 0.52282 \\
\hline
\end{tabular}

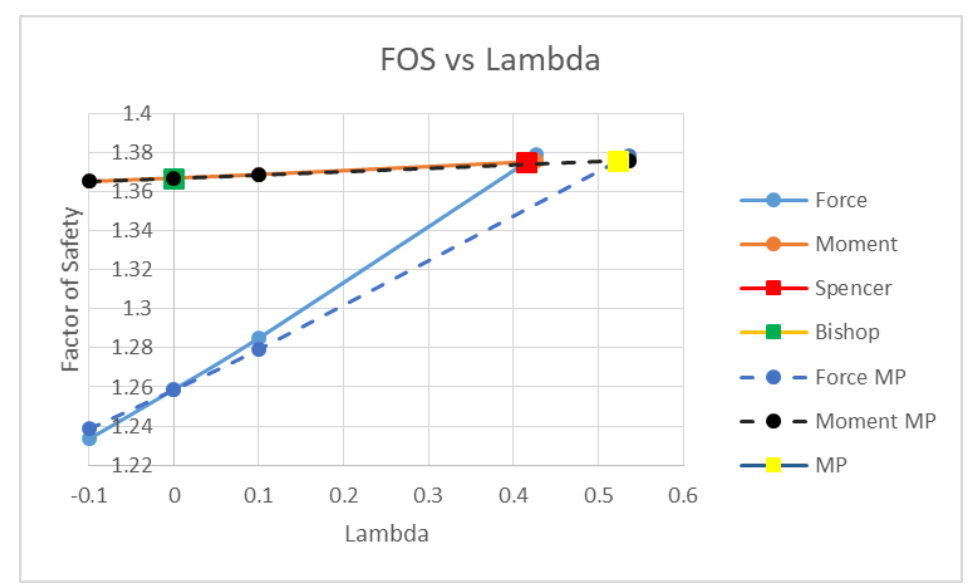

Figure 5. Factor of safety

\subsection{CONCLUSION}

This paper presents the calculation of both manual and software in order to obtain the factor of safety. There are limitations for manual calculation which give impact towards the accuracy of the factor of safety. For Spencer method, the manual calculation has lower factor of safety because of the limitation in Spencer charts that only allow $\phi^{\prime}$ d of up to $40^{\circ}$. All of the three methods tend to give almost a similar factor of safety as the moment equilibrium is insensitive to the interslice shear force assumption and the slope of moment equilibrium curve is almost horizontal. The lambda generated by Morgenstern-Price tends to be higher than Spencer because the halfsine function is used. Morgenstern-Price method has shown an outstanding reason why the method is referred to as the 'best-fit regression' which should be used to determine the factor of safety for many slopes due to its good polygon closure that considers both moment and force equilibrium, along with the usage of various interslice force functions. Based on the literature of unreinforced slope, the minimum factor of safety is 1.3 while the minimum FOS for reinforced or treated slope is 1.5. The selection of FOS is dependent on the minimum requirement that is set for specific type of slope. In this case, the minimum FOS that should be met is 1.3. Since Spencer gives a borderline value of FOS, this research chooses the value of FOS as the highest among all three methods. Hence, Morgenstern-Price is selected as the best method of slices to be used in calculation of FOS for slope stability analysis at this particular site location. This study has helped in determining the optimum FOS value for slope stability analysis. The selection on the right FOS value will reduce the probability of under-design and consequently, the probability of slope failure can be avoided.

\section{ACKNOWLEDGEMENT}

Authors would like to thank the Department of Civil Engineering, IIUM and School of Civil Engineering, UiTM for their contribution to this work.

\section{REFERENCES}

[1] Seequent. (2021). Stability modeling with GeoStudio 2021. Calgary, Alberta, Canada.

[2] Rahman, H. A. \& Mapjabil, J. (2017). Landslides Disaster in Malaysia: An Overview. Health and the Environment Journal, 8(1), 58-71. https://doi.org/ 10.1097/BLO.0b013e31814b9304

[3] Nuric, A., Nuric, S., Kricak, L., \& Husagic, R. (2013). Numerical Methods in Analysis of Slope Stability. International Journal of Science and Engineering Investigations, 2(14), 41-48. https://doi.org/2251-8843 
[4] Sutejo, Y., \& Gofar, N. (2015). Effect of area development on the stability of cut slopes. Procedia Engineering, 125, 331-337. https://doi.org/10.1016/j.proeng.2015.11.071

[5] Reale, C., Gavin, K., Prendergast, L. J., \& Xue, J. (2016). Multi-modal Reliability Analysis of Slope Stability. Transportation Research Procedia, 14, 2468-2476. https://doi.org/10.1016/j.trpro.2016.05.304

[6] Abramson, L. W., Lee, T. S., Sharma, S., \& Boyce, G. M. (2002). Slope stability and stabilization methods. John Wiley \& Sons.

[7] Jabatan Kerja Raya Malaysia. (2016). Geotechnical Engineering Handbook JKR.

[8] Cruden, D. M., \& Varnes, D. J. (1992). Landslides: investigation and mitigation. Chapter 3-Landslide types and processes. Transportation Research Board Special Report, (247).

[9] Budhu, M. (2011). Soil Mechanics and Foundations (3rd Edition). John Wiley \& Sons.

[10] Knappett, J., \& Craig, R. F. (2012). Craig's soil mechanics. CRC press. 